\title{
Comparing estimated cost per patient for dementia care: Two municipalities and Swedish national population data
}

\author{
Erik Jedenius ${ }^{* 1}$, A.Wimo ${ }^{1,2}$, J. Strömqvist ${ }^{3}$, J. Fastbom ${ }^{2}$, B. Winblad ${ }^{1}$, Ulrika Winblad ${ }^{4}$, N. Andreasen ${ }^{1,4}$ \\ ${ }^{1}$ Alzheimer Disease Research Center, Dept NVS, Karolinska Institutet, Stockholm, Sweden \\ ${ }^{2}$ Aging Research Center, Dept NVS, Karolinska Institutet, Stockholm, Sweden \\ ${ }^{3}$ Kalmar County Council, Primary Care unit, Sweden \\ ${ }^{4}$ Health services research, Department of Public Health and caring Sciences, Uppsala University, Sweden
}

Received: October 13, 2014

Accepted: January 18, 2015

Online Published: January 21, 2015

DOI: $10.5430 /$ cns.v3n2p67

URL: http://dx.doi.org/10.5430/cns.v3n2p67

\begin{abstract}
Aim: To evaluate a collaborative dementia program for its influence on cost and in which dementia care specialists and primary care centres collaborate with the municipality and, thereby, effect direct cost of dementia care.

Methods: The cost of illness (COI) study investigated the cost of dementia care to the municipality, specifically on the Municipality of Kalmar. Municipal costs in the Municipality of Älvsjö and national cost figures for Sweden were used as comparisons. The major costs related to dementia care, such as the cost of home care, day-care centers, and nursing home placement were extracted from municipality records.

Results: The yearly municipal cost per person with dementia in Kalmar ranged from $14,206 €$ to $26,334 €$ (17,684 USD to 32,780 USD) as compared to Älvsjö $10,610 €$ to $30,464 €$ (13,207 USD to 37,921 USD), and Swedish national figures showing costs from $23,600 €$ to $36,459 €(29,378$ USD to 45,384 USD), per patient, annual cost. In Kalmar, $60 \%$ of the patients with dementia received help from the municipality as compared to $69 \%$ in Älvsjö.

Conclusions: Implementation of such a dementia program is a recommendation that would not increase the cost for dementia care in the Municipality of Kalmar.
\end{abstract}

Key Words: Dementia, Alzheimer disease, Costs associated with dementia care, Dementia nurse, Health economy, Social welfare officer

\section{Introduction}

Social and economic consequences of dementia disorders present a challenge for any society. The estimated number of individuals with dementia worldwide is approximately 34.4 million $^{[1]}$ The corresponding number in Sweden in 2014 is 155,000 , with an expected increase to 250,000 by
2050. In 2005, the societal costs of dementia in Sweden were estimated at 5 billion $€$ in a population of approximately 9 million inhabitants, equivalent to $1.83 \%$ of the Gross Domestic Product. ${ }^{[2]}$ Thus, management of the disease has become a high priority for the authorities and politicians in Sweden. ${ }^{[3,4]}$

\footnotetext{
${ }^{*}$ Correspondence: Erik Jedenius; Email: erik.jedenius@ki.se; Address: Alzheimer Disease Research Center, Dept NVS, Karolinska Institutet, Minnesmottagningen M51, Karolinska Universitetssjukhuset Huddinge, Stockholm, Sweden.
} 
Dementing diseases are characterized by a wide range of symptoms that affect cognitive functions as well as ordinary activities of daily living. Moreover, neuropsychiatric symptoms in dementia are common sequela of dementing disorders and a driving force for nursing home admission, hence resulting in high costs for the municipalities. ${ }^{[5-7]}$

\subsection{Dementia organization in Sweden}

Medical dementia care is organized in Sweden mainly by the local county councils (CC), which provide for supervision and care during the early stages of dementia. In the later stages of dementia the supervision and care is mainly supported by the local municipalities (a self-government and administration mainly responsible for schooling, social and elderly care). Both CCs and municipalities have to follow national laws, regulations, and recommendations. ${ }^{[8]}$ The municipality is responsible for approximately $85 \%$ of the total cost of dementia, ${ }^{[9]}$ mainly due to nursing home costs.

In the Swedish health care model there is an intrinsic conflict between regional national governance concerning the standards of equality and equity. ${ }^{[10]}$ The Swedish government is responsible for ensuring that the health care system is efficient and that operational objectives, for instance, maintaining the standard of equal care to everyone. The regionally, Sweden is made up of county councils and the local municipalities, which enjoy a large measure of freedom to shape and carry out their own programs. In the case of providing dementia care that could lead to variable standards for dementia care in different counties and municipalities of the country. To better harmonize dementia care nationally, the Sweden's National Board of Health and Welfare promoted the 2010 "Nationella riktlinjer för vård och omsorg vid demensjukdom" (National Guidelines for Care in Dementia). ${ }^{[4]}$ Research on dementia care programs emphasizes that caregiver education postpones future nursing home placement. ${ }^{[11,12]}$ Also, symptomatic pharmacological treatment has been suggested to yield similar results. ${ }^{[13-15]}$

\subsection{The dementia program in Kalmar}

With increasing size of the elderly population, more people are expected to suffer from dementia, resulting in an increased economic burden for society in the future. Thus, it is important to meet this challenge with new care strategies. One example is the dementia disease management program in Kalmar, Sweden. The program's main objective is to detect dementia at an early stage in order and for the community to be engaged in the intervention and provide appropriate, individualized care throughout the course of the disease. ${ }^{[16-18]}$

The program involves from the CC the primary care specialist and dementia nurse, dementia specialists, and from the Municipality the social welfare officer in charge of support authorization. ${ }^{[17,18]}$ The program was built up step-by-step from 1998 to the middle of 2000. Remarkably, the program was implemented without any extra funding. To make this possible a horizontal functional organization involving representatives from the CC and the Municipality was established which encouraged collaboration to provide a chain of dementia care, addressing care needs from the earliest to the final stages of the disease. The program provides guidelines for management of care for patients with suspected dementia. Caregiver support and education are cornerstones of the program. The dementia program in Kalmar fulfills most of the criteria stated later in the national Swedish dementia guidelines. ${ }^{[4]}$ In 1998, an inventory was made of every person in the Kalmar municipality who had been diagnosed with a cognitive impairment. Five hundred and thirty-eight patients were identified as having either an established or a provisional diagnosis of dementia. The estimated number of persons with dementia, based on age specific prevalence figures, ${ }^{[9,19]}$ was approximately 900 . Registered nurses already working in primary care were appointed as dementia nurses (DN). In this program new possible cases are referred directly to the DN. The diagnostic process starts with the collection of necessary information about the patient, enabling the general practitioner (GP) to establish a diagnosis based on the ICD-10 system. ${ }^{[20]}$ Younger patients and complicated cases are referred to the dementia specialist at the local hospital. Primary care is the service, thus, which becomes mostly responsible for patient care in the milder phase of the disease. Later, when the need for support increased, responsibility shifts to the municipality, which can provide home care support initially, and nursing home services ultimately.

At the start of the program in 1998, approximately 30 patients with dementia were waiting for nursing home placement in Kalmar. After the dementia program had been in effect for two years the queue was eliminated without increasing the number of beds. Furthermore, the budget for elder care did not increase and the municipality incurred no increased costs as a result of the program (further analyses are presented elsewhere $\left.{ }^{[17,21]}\right)$.

\subsection{Purpose and objectives}

A key purpose of this project has been to analyze resource utilization and municipality cost of dementia care. The hypothesis presented here is that the cost of dementia remains unchanged with, and as a consequence of, the introduction of the dementia program. Thus, the objectives in the analyses, here, are to evaluate the effects of the dementia program and its influence on the direct cost of dementia care in the municipality.

\section{Material and methods}

A cost of illness (COI) study was designed to analyze the direct cost of dementia care in the municipality. The Kalmar Municipality county council's direct costs, costs of infor- 
mal care and indirect costs due to loss of patient productivity were not included. The assumption is that the dementia program, with its early intervention, will contribute to a reduction of the costs in the final stages of the disease, due to early education and support of patients and their caregivers, as well as proper medication that would correspond to a longer stay in one's own home (the program in total presented elsewhere). ${ }^{[16-18,21,22]}$ The study was approved by the ethics committee in Linköping (Dnr. 03-494) and in Stockholm at the Karolinska Institutet (Dnr. 239/03).

\subsection{Comparisons and data collection}

In order to examine representativeness of the area and program direct costs we compared Kalmar Municipality and Älvsjö Municipality, and Kalmar Municipality and Sweden national costs. ${ }^{[9]}$ Älvsjö was selected because it did not have a dementia program, and it was already included in a parallel study. In order to compare population size and socioeconomic status in these areas, information regarding education and income levels was obtained from Statistics Sweden. ${ }^{[23]}$ All costs were adjusted to the year 2002 based on the Consumer Price Index (CPI).

The costs for dementia care were extracted from the municipality records in Kalmar and Älvsjö. A cost analysis model was used that was made up of three basic components: (a) subtotals of resource expenditures, including all major municipality costs (MC) related to dementia care such as homecare, day-care centers, as well as temporary and permanent nursing home placement; ${ }^{[9]}$ (b) unit costs for each resource (see Table 1); and (c) the number of persons with dementia $(\mathrm{C} 1 . . \mathrm{Cn})$ that used this source information: $\mathrm{MC}=$ $(\mathrm{A} 1 \times \mathrm{B} 1 \times \mathrm{C} 1 .+. \mathrm{An} \times \mathrm{Bn} \times \mathrm{Cn})$.

The quantity (total) of each resource expenditure, within a specific time frame (A), was obtained from the municipality's administrative records in clerk's office that recorded approvals. The cost data in Kalmar and Älvsjö were extracted for three-month periods in order to illustrate variations during the year. The data from the Kalmar Municipality records were considered to be most accurate from 2002 to the present, due to better recordkeeping. The analysis was, therefore, carried out over the subsequent two-and-ahalf year period after the program was fully established and operating. ${ }^{[1]}$ Because the data from Älvsjö Municipality was missing data, we extended the data gathering period, from 2003 to 2005 , in order to minimize the effect of the missing data. To reduce the risk of confounding variables in the comparison, we only gathered diagnosis and cost data from municipal records for comparison only of the yearly cost of elderly municipality care in these two areas.

The cost for support provided by the municipality was gathered from the cost rates charged by the Kalmar and Älvsjö municipalities, respectively. Further, the same unit costs were used in both areas in the final calculations. Overhead costs were set to an estimated $20 \%$ and included in the analysis (see Table 1). The three-month data was summed up as annual costs. In addition, we compared these findings to the estimated cost of dementia in Sweden. ${ }^{[9]}$

Table 1: Municipality costs for supporting individuals with dementia in 2003 ( $1 €=9.5$ Swedish Crown $[\mathrm{SEK}]=1.25$ USD)

\begin{tabular}{llll}
\hline & SEK & $€$ & USD \\
\hline Support in home & 291/hour & 27.7/hour & 34/hour \\
Day care center & 630/day & 60/day & 73.7/day \\
Nursing home & 1,386/day & 118/day & 145/day \\
\hline
\end{tabular}

\subsection{Statistic and data processing}

Statistical software (SPSS, version ten) and a spreadsheet (Microsoft Excel) were used for the statistical analyses. All variables were summarized using standard descriptive statistics, such as mean, standard deviation, and frequency. Comparisons were made between national and local data on gender, age, costs and frequency of patents with dementia, all based upon population data.

\section{Results}

\subsection{Demographics}

There were no major demographic changes in the two municipalities and Sweden as a whole during the period from 2000 to 2007. The age structure in Kalmar Municipality was similar to the whole of Sweden, whilst Älvsjö had a younger population (see Table 2). We found a slightly higher proportion of elderly woman in Kalmar as compared to nationally. In Älvsjö the proportion of people with a higher education was larger than in Kalmar and Sweden. The proportion of higher income was highest in Älvsjö (38.9\%), followed by Sweden as a standard (25\%) and Kalmar (22.2\%). The number of nursing homes beds in Kalmar was lower than Älvsjö (a substantial of the beds where used by other municipalities in the Stockholm area, thus difficult to compare) and in Sweden as a whole.

Between January 2002 and June 2004, 570 persons with dementia were identified in the records of the Kalmar Municipality (see Table 2). Most of them had several forms of support, such as intermittent hours of homecare, regular home care, day care and home care. However, the number of suspected cases is higher. Based on demographics and description statistics of age, the estimated number of individuals with dementia in Kalmar Municipality in 2003 was estimated to be 950 . The Kalmar records show 84 existing dementia cases in 2003 that are receiving care from the municipality. Further, based on epidemiological study findings, ${ }^{[9,19]}$ an estimated 150 deaths occur yearly amongst individuals in Kalmar Municipality with dementia was 150 per year. Thus the records indicate that approximately $40 \%$ 
died without using any municipal resources.

In Älvsjö, 189 patients with dementia were identified between January 2002 and December 2005 (see Table 2). The estimated number of persons with dementia in in Älvsjö Municipality in 2003 was 293. On average, nine patients died per three month period (or 36/year). The estimated number of deaths amongst people with dementia in Älvsjö was 50 per year. Thus, $31 \%$ died without using any mu- nicipality resources in Älvsjö. Descriptive statistics were performed on variables, including population, education and income levels (High, defined as the high quartile in Sweden) in the three different study areas; as well as on total number of patients with dementia noted in the municipal records in Kalmar and Älvsjö during the observation periods. Regarding Älvsjö, an estimation was made that was proportional to the other municipality.

Table 2: Descriptive statistics in Kalmar and Älvsjö

\begin{tabular}{|c|c|c|c|c|c|c|}
\hline & Population & $\begin{array}{l}\text { Proportion } 65 \\
\text { and elderly }\end{array}$ & $\begin{array}{l}\text { Estimated number } \\
\text { with dementia }\end{array}$ & $\begin{array}{l}\text { Estimated new } \\
\text { cases per year }\end{array}$ & $\begin{array}{l}\text { Number of } \\
\text { beds }\end{array}$ & $\begin{array}{l}\text { Number of } \\
\text { beds } / 1,00065+\end{array}$ \\
\hline \multicolumn{7}{|l|}{ Sweden } \\
\hline Population & $8,919,814$ & $17 \%$ & 144,623 & 25,776 & 111,793 & 71 \\
\hline Education (\% high) & $25 \%$ & $17 \%$ & & & & \\
\hline Income (\% high) & $25 \%$ & & & & & \\
\hline \multicolumn{7}{|l|}{ Kalmar } \\
\hline Population & 60,415 & $17 \%$ & 949 & 165 & 560 & 53 \\
\hline Education (\% high) & $28 \%$ & $19 \%$ & & & & \\
\hline Income (\% high) & $22.2 \%$ & & & & & \\
\hline $\begin{array}{l}\text { Number of patients in the } \\
\text { municipal records 2002-Q2 } 04\end{array}$ & 570 & & & & & \\
\hline \multicolumn{7}{|l|}{ Älvsjö } \\
\hline Population & 21,067 & $15 \%$ & 298 & 52 & $95+250^{*}$ & $111^{*}$ \\
\hline Education (\% high) & $37 \%$ & $25 \%$ & & & & \\
\hline Income (\% high) & $38.9 \%$ & & & & & \\
\hline $\begin{array}{l}\text { Number of patients in the } \\
\text { municipal records 2002-2005 }\end{array}$ & 189 & & & & & \\
\hline
\end{tabular}

\subsection{Municipality costs related to dementia}

The Kalmar Municipality cost for dementia remained relatively stable during the observation period (adjusted according to CPI) (see Figure 1). The cost for dementia care within the municipality constituted about 40 percent of the total costs for elder care in the Kalmar Municipality and these costs remained stable between 2001 and 2005 (adjusted according to CPI), increasing by $2.8 \%$ per year.

The Älvsjö Municipality Dementia costs could not be assessed fully due, primarily, to incomplete knowledge of diagnose. Later, improvement in the program, enabling more consistent and accurate recording of dementia diagnoses, the total cost for dementia care was estimated to equal one third of the total cost for elderly care in the Älvsjö Municipality, increasing at $5.7 \%$ per year, which was faster rate than the CPI (see Figure 1).

\subsection{Demographic and cost}

In summary, municipality records from the study period showed that the proportion of patients with a dementia di- agnosis that utilized resources was $61 \%(n=576$ of estimated 949) in Kalmar and 63\% ( $n=187$ of estimated 298) in Älvsjö (see Table 3). Assuming that all other persons with dementia that not are included in the cost model are non-users of care, the yearly municipality cost per patient (based on the estimated total number of persons with dementia) in Kalmar was 14,206 $€$ (in year 2003), in comparison to $10,610 €-13,184 €$ in Älvsjö (in years 2003-2005). The corresponding national cost in Sweden was $23,600 €$ and $29,871 €$ in 2000 and 2005 respectively. ${ }^{[4,9]}$ However, based on the actual number of persons that are included in the cost model, the cost per person with dementia in Kalmar 2003 was 26,334 $€$, and in Älvsjö this cost was estimated between $26,025 €$ to $30,464 €$ (see Table 3). Comparatively, the estimated corresponding cost is $36,459 €$ in Sweden. ${ }^{[4,9]}$

\section{Discussion}

To our knowledge, this is the first, detailed cost study of dementia in Sweden that compares two municipalities. When 
a diagnostic program is introduced in an area and costs are analyzed, the resulting cost during a follow-up period may be difficult to interpret. First, previously unmet needs must be identified, which will lead to new types of expenditures. Second, reclassification of medical cases that were previously assigned other diagnoses but that now match the criteria for dementia in this program. Finally, new, though previously undiagnosed cases, are identified, with or without unmet needs, where early identification has led to cost effective care? The latter is probably difficult to determine in a study such as this.

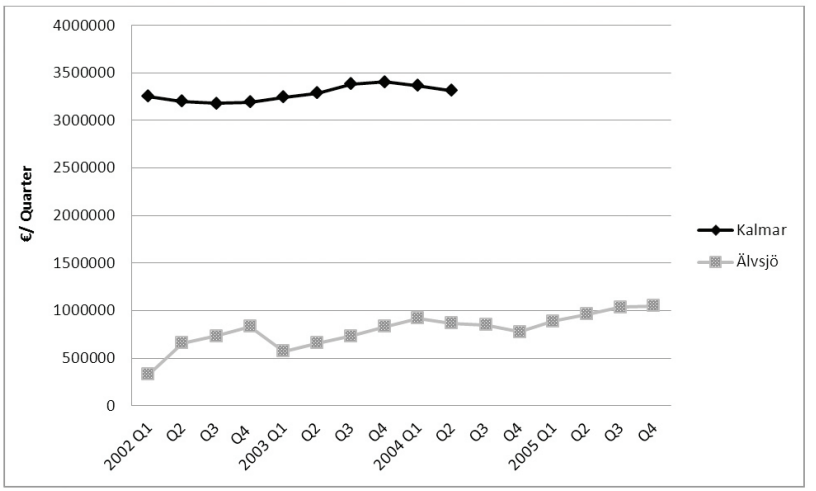

Figure 1: The total municipality cost (€/Quarter) in Kalmar (2002 to 2004 Q2) and Älvsjö (2002 to 2005) due to patients suffering from dementia

\subsection{Comparability in this setting}

Choosing the variable, estimated cost per patient for dementia care (home care, nursing homes, etc.), enabled comparison across the divergent data sets. Such costs are expressed in two ways: i) cost based on the actual population, and ii) cost derived from the incidence rate of persons with dementia, specific to the particular region, and fixed to a defined period of time in the analyses. The Kalmar and Älvsjö municipalities' data, which can be regarded as bottom-up studies, were compared to the national cost estimates. The latter are based on mixed analytic approaches, specifically bottom up and top down studies. ${ }^{[9]}$

How to address comparability was an important issue to consider. In the first approach to calculating costs in Kalmar and Älvsjö, the unit of investigation referred to a count of users of formal dementia care. Such a cost approach, since it counts the whole dementia population in respective study areas, would overestimate since non-care users would be counted among with the total population having dementia, the data for whom were not analyzed. On the other hand, if the total cost (for example in Kalmar 13.5 million $€$ in 2003, based on 415 persons) is assumed to represent all expenditures made to care for the entire dementia populations in the each study areas, e.g. 949 persons in Kalmar, it is implicitly assumed that those not included (949-415 persons) are nonusers of care. This subset of the population in the Kalmar
Municipality is not easy to extract from the records, and it is unknown how many of these 415 are truly non-users, also missing are individuals with dementia diagnoses but who receive care from the dementia nurse and caregiver. Moreover, those not diagnosed with dementia, a subset which probably contains many with mild dementia, as well as those incorrectly classified may have utilized resources, resulting in an underestimate of costs. Thus the range of costs per individual with dementia in Kalmar 14,206 $€$ to $26,334 €$ can be regarded as a min-max interval. Compared to the corresponding Swedish cost estimate for municipal care, which is a range of $29,871 €$ to $36,459 €$, one would conclude that cost-per-individual-with-dementia is lower in Kalmar than nationally. This interpretation is supported by the lower standardized number of beds-per-1,000 for long term care in Kalmar Municipality (53 beds per 1,000 65+) as opposed to Sweden (71 beds per 1,000 65+), noting that long term care is the major cost driver of elder care.

The implementation of the program in Kalmar caused a great deal of media attention which created enthusiasm among the staff. Such enthusiasm may have had a positive effect on the results. The somewhat lower cost in Kalmar during the same period could just be a coincidence. The difference in costs in Älvsjö Municipality compared to Sweden could be explained by the fact that some patients still were not diagnosed with dementia. As a consequence of the new program the social welfare officers became more aware of the benefits of reliable data, and data gathering was approached with more care and interest after 2004. Doubtless, patients and caregivers in Kalmar have also benefited from the dementia program, having received better care while it was in place. The program should be revisited to determine if these results are sustainable over a longer period of time.

If we assume that the program in Kalmar reduces municipality cost, or is at least does not increase cost, it should be regarded as successful. First, in the program where most patients were identified early in the disease which suggest to facilitates early intervention and support such as care planning, caregiver support and training, drug review, ${ }^{[17]}$ and symptomatic drug treatment. Further where the use of sedatives, drugs with anticholinergic properties and antipsychotics stabilized and in some cases decreased. ${ }^{[16]}$

Secondly, a program strategy is to engage the dementia nurse as a mentor to the caregiver(s) throughout the course of the disease. The support and education the caregiver receives from the dementia nurse to support ordinary, daily activities is a most valuable contribution.

Thirdly, the social welfare officers become involved in the patient and caregivers' situation early in the disease, and can facilitate support when should the time come for home care or nursing home placement. Fourthly, caregivers can better cope with their situation when they know that support is available. Finally, if a problem arises the program provides 
accessibility to helpful and likely resources, including the dementia nurse and the physician. All of these benefits may have a positive influence on cost and utilization of care resources. Moreover, they may signify an improvement in the quality of care as a result of the program. ${ }^{[17]}$ In addition, sustainable pharmacologic approaches can be viewed as a sign of cost effectiveness, for instance reduced use of neuroleptics and sedatives in the elderly, which have untoward behavioral effects, and improved strategic use of medications used to manage the symptoms of dementia ${ }^{[16]}$ suggests associated with cost-benefit.

Table 3: Municipality costs in elder care related to dementia in Kalmar (2003) and Älvsjö derived from the municipality records

\begin{tabular}{|c|c|c|c|c|c|c|c|c|}
\hline \multirow{2}{*}{ Municipality costs } & \multicolumn{2}{|c|}{ Kalmar Municipality(2003) } & \multicolumn{2}{|c|}{ Älvsjö Municipality(2003) } & \multicolumn{2}{|c|}{ Älvsjö Municipality(2004) } & \multicolumn{2}{|c|}{ Älvsjö Municipality(2005) } \\
\hline & $€$ & $\%$ & $€$ & $\%$ & $€$ & $\%$ & $€$ & $\%$ \\
\hline \multicolumn{9}{|l|}{ Elderly care cost } \\
\hline Home care & $13,363,238$ & 40 & $4,821,846$ & 40 & $5,372,023$ & 43 & $5,867,157$ & 43 \\
\hline Day care & 879,903 & 3 & 265,777 & 2 & 303,761 & 2 & 294,384 & 2 \\
\hline $\mathrm{NH}$ and Respite care & $19,352,667$ & 57 & $6,945,782$ & 58 & $6,945,782$ & 55 & $7,586,729$ & 55 \\
\hline SUM & $33,595,808$ & 100 & $12,033,405$ & 100 & $12,621,566$ & 100 & $13,748,270$ & 100 \\
\hline \multicolumn{9}{|l|}{ Dementia care cost } \\
\hline Home care & $2,598,858$ & 19.3 & 156,902 & 5 & 157,149 & 5 & 34,563 & 9 \\
\hline Day care centres & 490,573 & 3.6 & 44,276 & 1.4 & 118,555 & 3 & 150,935 & 4 \\
\hline Respite care & 645,790 & 5 & 111,282 & 4 & 67,320 & 2 & 85,759 & 2 \\
\hline Permanent NH & $9,746,718$ & 72 & $2,849,389$ & 90 & $3,071,413$ & 90 & $3,350,482$ & 85 \\
\hline SUM & $13,481,939$ & 100 & $3,161,849$ & 100 & $3,414,437$ & 100 & $3,928,739$ & 100 \\
\hline $\begin{array}{l}\text { Estimated number with } \\
\text { dementia }\end{array}$ & 949 & & 298 & & 298 & & 298 & \\
\hline $\begin{array}{l}\text { Cost per patient vs. } \\
\text { estimated }\end{array}$ & $14,206 €$ & & $10,610 €$ & & $11,458 €$ & & $13,184 €$ & \\
\hline Dementia care cost \% & & 40 & & 26 & & 27 & & 29 \\
\hline $\begin{array}{l}\text { Number of patients in the } \\
\text { model (SD) }\end{array}$ & $415( \pm 4.7)$ & & $81( \pm 19.6)$ & & $109( \pm 9.8)$ & & $127( \pm 10.5)$ & \\
\hline $\begin{array}{l}\text { Cost per patient in the } \\
\text { model (SD) }\end{array}$ & $\begin{array}{l}26,334 € \\
(15,955 €)\end{array}$ & & $\begin{array}{l}29,040 € \\
(18,845 €)\end{array}$ & & $\begin{array}{l}26,025 € \\
(18,956 €)\end{array}$ & & $\begin{array}{l}30,464 € \\
(18,585 €)\end{array}$ & \\
\hline
\end{tabular}

\subsection{Comparability in the literature in a similar con- text}

There are few studies in the literature that focus on the cost of dementia in a municipal setting. In a study from Nordanstig in Northern Sweden, ${ }^{[24]}$ the municipal cost per person with dementia was approximately $29,000 €(36,118$ USD) per year, which compares to the upper interval (see Table 3) of the range of estimated costs in Kalmar Municipality. Studies have examined programs that focus on the primary care level, primarily including diagnostic procedures, ${ }^{[25-29]}$ caregiver education and caregiver burden. ${ }^{[11,28]}$ Some studies have investigated dementia management programs that served patients in more severe stages of the illness, ${ }^{[11,12,25,26]}$ while others studied fragile elderly individuals with or without dementia. ${ }^{[30-32]}$ Those projects that most resemble ours have evaluated caregiver support programs and their effect on the length of time from diagnosis to nursing home placement, and such studies have been suggestive that better support to caregivers can lengthen that time. To compare the results from these studies with the Kalmar project is problematic. Often, the former studies include severely ill patients or patients with specific problems. The population in our study included patients with all forms of dementia, at all levels of cognitive impairment. In spite of these selection criteria and other limitations, these projects and programs tend to show both health and economic benefits for the patients and their caregivers.

\subsection{Limitations}

Our study has several limitations including aspects of population, diagnose, costs and general.

\subsubsection{Population}

Comparability between data obtained for the municipality level - Kalmar, Älvsjö, and national Swedish data, in terms of the study populations differed between study areas. The populations of Kalmar Municipality and the whole of Sweden are demographically quite similar regarding proportion of elderly. Älvsjö, on the other hand, has a somewhat younger population and which is on-average more highly educated.

\subsubsection{Diagnose}

Since the data gathered from the municipality records did not have a controlled diagnostic certainty, we cannot know the true number of persons with dementia in the study areas. We chose to assume that age- and class-specific prevalence 
obtained from epidemiological studies were valid to reflect Kalmar, Älvsjö and Sweden as a whole. Likewise, we do not know the validity of the dementia diagnoses in the municipal records at the time the data was gathered. Further where no such information is available in earlier municipality records as the municipalities did not record diagnoses.

\subsubsection{Cost}

Comparability between data obtained for the municipality level regarding how the cost per case was calculated. Thus, the data in Kalmar was collected during a stable phase of the program. This could explain why we did not find any major differences in costs during the observation time. In the period before and during the implementation of the program, the budget for elderly care was unchanged in Kalmar, which supports the results of this study.

Furthermore, in Älvsjö, the database from the year 2002 to 2005 showed an increase of cost for dementia care. This probably reflects the fact that the data from Älvsjö was initially limited regarding the low number of diagnosed patients. By the end of the period the number of identified patients with dementia in the municipality had increased, possibly as a result of the focus on gathering accurate dementia data. However, stabilization of the costs was never reached in Älvsjö during the observation period.

\subsubsection{General limitations}

Another limitation in our study was that we did not account for the differences in local traditions and regulations that were the basis for type and extent of support provided by the municipalities for dementia care. Examples include variations in social welfare officers' education, local budget allocations and different data storage. As mentioned above, it is uncertain that our bottom-up approach captured all the patients with dementia who are using municipality resources. However, very few patients are known to have been missing in the records due to the long period of the program. If patients are missing, they are probably utilizing municipal recourses for health reasons other than dementia. This must be evaluated in future studies. Thus, if dementia was the problem they would be included in the dementia program and be supported.

There is a need for further controlled prospective studies regarding the cost effectiveness of early identification of people with dementia. Whether the design should include control areas or randomization on the individual level is a matter for discussion. With both designs there is a risk of contamination with the intervention program.

\section{Conclusions}

With respect to the limitations in our study, we suggest that the dementia program has been implemented without increasing cost for dementia care in the Municipality of Kalmar, during the period from 2001 through the second quarter of 2004. The lower cost for the municipality could have led to cost displacement, with higher cost in the primary care system. As shown in a previous study ${ }^{[17]}$ the dementia program was implemented and did operate in primary care with an unchanging budget via reallocation of resources, which supports the notion that the program is cost effective from the viewpoint of the municipality and of primary care.

\section{Acknowledgements}

All patients, caregivers and the staff of the primary care units in Kalmar and Älvsjö Municipality. A special thanks to the staff in Kalmar; Margareta Johansson, Anneli Adolfsson, Marianne Jakobsson, Helen Holmström Ann-Christin Arvidsson, Katarina Jervelind, Janet Mosén, Monica Svannäs, Philip Johansson, Maud Löfström, Margareta Johansson and Gunvor Adolfsson. Älvsjö Municipality; Anette Ekengren and Hans Stavrot. The city of Stockholm; Anders Håkanson. Special support and guidance from; Mona Khilgren and Stellan Båtsman. Thanks to Fredrik Hjärthag and Gunnar Edman for statistical support. A warm thanks to the Swedish Alzheimer Foundation and the Foundation for the Memory of Ragnhild and Einar Lundström. Finaly for economic support for my $\mathrm{PhD}$ education is partly guaranteed by Janssen Sweden.

\section{References}

[1] Wimo A, Winblad B, Jonsson L. The worldwide societal costs of dementia: Estimates for 2009. Alzheimers Dement. $2010 \mathrm{Mar}$; 6(2): 98-103. PMid:20298969. http://dx.doi.org/10.1016/j.jal z.2010.01.010

[2] Wimo A, Prince M. Alzhiemer's Disease International World Alzheimer Report 2010. London UK: Alzhimer's Disease International (ADI); 2010.

[3] SBU. Dementia diseases. Stockholm: SBU-The Swedish Council on Technology Assessment in Health Care; 2008.
[4] SOS TNBoHaW. Nationella riktlinjer för vård och omsorg vid demenssjukdom. [National guidelines for care in dementia]. 2010.

[5] Beeri MS, Werner P, Davidson M, Noy S. The cost of behavioral and psychological symptoms of dementia (BPSD) in community dwelling Alzheimer's disease patients. International journal of geriatric psychiatry. 2002 May; 17(5): 403-8. PMid:11994927. http: //dx.doi.org/10.1002/gps. 490

[6] Grossberg GT. The ABC of Alzheimer's disease: behavioral symptoms and their treatment. Int Psychogeriatr. 2002; 14 Suppl 1: 2749. PMid:12636179. http://dx.doi .org/10.1017/S10416102 03008652

[7] Herrmann N, Lanctot KL, Sambrook R, Lesnikova N, Hebert R, 
McCracken P, et al. The contribution of neuropsychiatric symptoms to the cost of dementia care. International journal of geriatric psychiatry. 2006 Oct; 21(10): 972-6. PMid:16955429. http: //dx.doi.org/10.1002/gps.1594

[8] Magnussen J, Vrangbaek K, Saltman R. Nordic Health Care System, Recent Reforms and Current Policy Challanges. 1 ed. Maidenhead: Opend University Press; 2009.

[9] Wimo A, Jonsson L, Johansson L. Demenssjukdomarnas samhällskostnader och antalet dementa i Sverige 2005. Stockholm: The National Board of Health and Wellfare; 2007.

[10] Fredriksson M, Winblad U. Consequences of a decentralized healthcare governance model: measuring regional authority support for patient choice in Sweden. Soc Sci Med. 2008 Jul; 67(2): 2719. PMid:18450346. http://dx.doi.org/10.1016/j.socscim ed. 2008.03 .025

[11] Andren S, Elmstahl S. Effective psychosocial intervention for family caregivers lengthens time elapsed before nursing home placement of individuals with dementia: a five-year follow-up study. Int Psychogeriatr. 2008 Jul 8: 1-16.

[12] Brodaty H, Green A, Koschera A. Meta-analysis of psychosocial interventions for caregivers of people with dementia. J Am Geriatr Soc. 2003 May; 51(5): 657-64. PMid:12752841. http://dx.doi .org/10.1034/j.1600-0579.2003.00210.x

[13] Fillit H, Hill J. The economic benefits of acetylcholinesterase inhibitors for patients with Alzheimer disease and associated dementias. Alzheimer Dis Assoc Disord. 2004 Apr-Jun; 18 Suppl 1: S249. PMid:15249845. http://dx.doi.org/10.1097/01.wad.00 $00127492.65032 . d 3$

[14] Getsios D, Caro JJ, Caro G, Ishak K. Assessment of health economics in Alzheimer's disease (AHEAD): galantamine treatment in Canada. Neurology. 2001 Sep 25; 57(6): 972-8. PMid:11571319. http://dx.doi.org/10.1212/WNL.57.6.972

[15] Wimo A, Winblad B. Economic aspects on drug therapy of dementia. Curr Pharm Des. 2004; 10(3): 295-301. http://dx.doi.org $/ 10.2174 / 1381612043386400$

[16] Jedenius E, Johnell K, Fastbom J, Strömqvist J, Winblad B, Andreasen N. Dementia Management Program in a Community Setting and the Use of Psychotropic Drugs in the Elderly Population. Scandinavian Journal of Primary Health Care. 2011. PMid:21740344. http://dx.doi.org/10.3109/02813432.2011.585277

[17] Jedenius E, Wimo A, Stromqvist J, Andreasen N. A Swedish programme for dementia diagnostics in primary healthcare. Scand J Prim Health Care. 2008; 26(4): 235-40. PMid:18788054. http: //dx.doi.org/10.1080/02813430802358236

[18] LT.Kalmar. Demensprogram för omsorg och vård till personer med demenssjukdom i Kalmar län. [Dementia Program of care provision for people with dementia in California]. 2012 [cited 2012 September 19]. Available from: http://www. Itkalmar.se/for-vardg ivare/demensprogram/

[19] Wimo A, Jönsson L, Johansson L. Äldreuppdraget. In: Wellfare TNBoHa, ed.: The National Board of Health and Wellfare; 2000.

[20] WHO. WHO international classifications, ICD 10. WHO 2008.
[21] Jedenius E, Wimo A, Stromqvist J, Jonsson L, Andreasen N. The cost of diagnosing dementia in a community setting. International journal of geriatric psychiatry. 2009 Aug 14.

[22] Strömqvist J, Jedenius E. Vårdprogram Demens i Kalmar län - en modell för Sverige? Incitament. [Dementia care program in California - a model for Sweden? incentives]. 2005(4): 342.

[23] Sweden SS. Population statistics 2000-5. Description of the population in Sweden. SCB. Statistics Sweden 2008.

[24] Wimo A, Johansson L, Jonsson L. [Prevalence study of societal costs for dementia 2000-2005. More demented people-but somewhat reduced costs per person]. Lakartidningen. 2009 Apr 28-May 12; 106(18-19): 1277-82. PMid:19537500.

[25] Downs M, Turner S, Bryans M, Wilcoock J, Keady J. Effectivness of educational interventions in improving detection and management of dementia in primary care: cluster randomised controlled study. BMJ. 2006; 332: 692-6. PMid:16565124. http://dx.doi.org/1 $0.1136 / \mathrm{bmj} .332 .7543 .692$

[26] Harvan JR, Cotter V. An evaluation of dementia screening in the primary care setting. J Am Acad Nurse Pract. 2006 Aug; 18(8): 351-60. PMid:16907696. http://dx.doi.org/10.1111/j.174 5-7599.2006.00137.x

[27] Olafsdottir M, Marcusson J. Diagnosis of dementia at the primary care level. Acta Neurol Scand Suppl. 1996; 165: 58-62. PMid:8740990. http://dx.doi.org/10.1111/j.1600-0404. 1996.tb05873.x

[28] Olafsdottir M, Skoog I, Marcusson J. Detection of dementia in primary care: the Linkoping study. Dement Geriatr Cogn Disord. 2000 Jul-Aug; 11(4): 223-9. PMid:10867449. http://dx.doi.org/1 $0.1159 / 000017241$

[29] Lessig M, Farrell J, Madhavan E, Famy C, Vath B, Holder T, et al. Cooperative dementia care clinics: A new model for managing cognitively impaired patients. J Am Geriatr Soc. 2006 Dec; 54(12): 1937-42. PMid:17198502. http://dx.doi.org/10.11 $11 / j \cdot 1532-5415.2006 .00975 . x$

[30] Melis RJ, Adang E, Teerenstra S, van Eijken MI, Wimo A, van Achterberg T, et al. Cost-effectiveness of a multidisciplinary intervention model for community-dwelling frail older people. J Gerontol A Biol Sci Med Sci. 2008 Mar; 63(3): 275-82. PMid:18375876. http://dx.doi.org/10.1093/gerona/63.3.275

[31] Melis RJ, van Eijken MI, Teerenstra S, van Achterberg T, Parker SG, Borm GF, et al. A randomized study of a multidisciplinary program to intervene on geriatric syndromes in vulnerable older people who live at home (Dutch EASYcare Study). J Gerontol A Biol Sci Med Sci. 2008 Mar; 63(3): 283-90. PMid:18375877. http://dx.doi.org/10.1093/gerona/63.3.283

[32] Vickrey BG, Mittman BS, Connor KI, Pearson ML, Della Penna RD, Ganiats TG, et al. The effect of a disease management intervention on quality and outcomes of dementia care: a randomized, controlled trial. Annals of internal medicine. 2006 Nov 21; 145(10): 713-26. PMid:17116916. http://dx.doi.org/10.73 26/0003-4819-145-10-200611210-00004 